\title{
CODATO, Adriano; PERISSINOTO, Renato; FUKS, Mário; BRAGA, Sérgio (orgs). Quem governa? Um estudo das elites políticas do Paraná. Curitiba: Editora UFPR, 2007. 354p.
}

\author{
Leonardo David Micheleto ${ }^{1}$
}

- Enviado em 29/01/2016

- Aprovado em 03/02/2016

Os estudos de grupos dominantes têm uma grande tradição na Sociologia e, mais recentemente, na Ciência Política, com destaque para as produções de Robert Dahl na década de 1970, a quem foi prestado homenagem no título desta obra, e para as produções de Mills, Mosca e Michels, que inauguraram um novo campo, no estudo de elites políticas. Há uma tendência, inclusive no Brasil, de se estudar as elites nacionais, suas redes, organizações, produções legislativas, relações entre os poderes, etc. Porém, para se configurar o jogo político e as elites a nível federal, há todo um jogo político e elites atuantes a nível regional, que são fundamentais na estruturação do sistema político nacional. Esses estudos estão começando a ganhar mais relevância. O Paraná, que não é considerado dos estados principais do país, mas que tem uma forte relevância, carece de estudos aprofundados sobre o tema, e é com o intuito de dar um pontapé inicial nesses estudos que os organizadores de Quem Governa? resolveram dar vazão ao projeto.

Entre os organizadores, temos os pesquisadores Renato Perissinotto, Adriano Codato e Sérgio Braga, que são professores de Ciência Política da Universidade Federal do Paraná, e Mário Fuks, que é professor da Universidade Federal de Minas Gerais. Entre esses e os demais pesquisadores que fizeram parte da produção dessa obra, muitos participam ou participaram do

\footnotetext{
${ }^{1}$ Graduado em História pela Universidade Federal do Paraná. Membro do Núcleo de Estudos Paranaenses (NEP). Endereço eletrônico: leonardo_micheleto@ hotmail.com
} 
Núcleo de Pesquisa em Sociologia Política Brasileira, dentre bolsistas e coordenadores, e alguns compõem hoje o Observatório de elites políticas paranaenses.

Para realizar a pesquisa utilizam o "método posicional", em que o poder político é exercido pelos indivíduos que controlam formalmente as instituições políticas de dada comunidade. Utilizam esse método para analisar os processos decisórios. Isso pode parecer uma limitação em relação ao "poder real", que pode ser exercido por indivíduos ou grupos de fora das instituições formais. Porém, segundo os autores, em sociedades complexas é pouco provável que o "poder real" esteja completamente separado do "poder formal", assim sendo, o método posicional pode ser visto como um passo anterior, e não um artifício oposto, à analise de decisões concretas.

São três as instituições estudadas: administradores públicos, parlamentares e líderes dos partidos políticos, durante o período de 1995 a 2002, os dois mandatos de Jaime Lerner como chefe do governo executivo do estado, e com o critério de permanência de no mínimo 90 dias no cargo. Sobre a coleta de dados, como não havia informações sobre os membros da elite política arquivadas nas instituições públicas, como se deveria, utilizam um questionário em cinco blocos, contendo dados iniciais, sobre a carreira política, valores políticos, comportamento político dos deputados, recursos sócioeducacionais, com o objetivo de traçar o perfil social, profissional e ideológico e analisar o comportamento em alguns processos decisórios concretos. São entrevistados $62 \%$ do total do universo original, considerado uma alta taxa de retorno, o que permite generalizações para o conjunto da elite política paranaense no período analisado.

A obra contém uma Introdução, quatro Partes com três Capítulos em cada Parte (sendo as três primeiras Partes com os Capítulos divididos por tipo de elite e a última com estudos de caso qualitativos) e uma Conclusão. A Parte I: O perfil das elites paranaenses traz o perfil das elites a partir dos seus atributos adstritos (raça, religião, sexo) e atributos conquistados (profissão, estrato social, escolaridade), além do perfil ideológico e profissão dos pais, tudo para analisar os filtros até chegarem à elite. Há uma prevalência absoluta de homens, brancos e católicos nos três segmentos, com alta escolaridade (maioria com grau universitário completo e formados pela Universidade Federal do Paraná) e provenientes dos segmentos médios e altos da sociedade. Os atributos adstritos não são suficientes para explicar o recrutamento da elite, pois há uma boa parte da população que possui esses atributos e não são recrutados. Assim sendo, para a coesão da elite também se torna necessário o conhecimento de sua socialização, treinamento e carreira prévios. Nesse caso, temos uma grande maioria de profissionais liberais, funcionários públicos e políticos. A escola e o título que ela confere parecem ser condições incontornáveis para o acesso à elite e seu principal "capital". 
Também é pesquisado a carreira que os pais ocuparam por mais tempo, a fim de perceber suas condições sociais. Aí os resultados são reveladores: na elite parlamentar, por exemplo, vemos que $63,3 \%$ dos pais foram proprietários por mais tempo, dentre pequenas, médias e grandes propriedades. Já na elite partidária um outro atributo chama a atenção: $28,6 \%$ dos pais tiveram atividade política regular, número considerado pequeno pelos autores, a ponto de afirmarem que essa elite não constitui uma oligarquia familiar. Essa afirmação mostra uma limitação admitida pelos próprios autores, de não alcançar as relações de nepotismo e oligarquias familiares. Considerando que só foram considerados os pais dos indivíduos das elites, $28 \%$ pode ser considerado um número alto, contando que as relações familiares dentro do poder público podem se dar de outras formas: irmãos, cunhados, genros, etc. Dado que uma parte considerável dos pais foram proprietários e políticos por muito tempo, pode-se aí começar uma reflexão sobre uma possível classe dominante, ainda mais dada a história do país. Mais um dado relevante nessa discussão é o fato de, na elite partidária, os indivíduos de esquerda são relacionados com o estrato social médio e os de direita e centro são relacionados com o estrato alto. Já na elite parlamentar não se estabelece correlação entre origem social e partido político, a opção parece ter a ver mais com a socialização política prévia.

Já a Parte II: Carreira política das elites paranaenses mostra os tipos de cargos ou posições que os indivíduos assumiram antes de assumir os postos de poder. Aqui se revela uma pluralidade de elites, com as diferentes elites tendo características próprias com diferentes habilidades valorizadas. A hipótese apresentada pelos autores é a de que a elite político-administrativa tem uma relação direta com o perfil político do governador, com a ideologia do Governo Lerner de superioridade da técnica sobre a política, muito veiculada nas suas propagandas, como se fosse um governo politicamente neutro. $91 \%$ dessa elite tiveram algum emprego público antes de assumir seu posto, e $65 \%$ nunca ocupou um cargo eletivo. Também a maioria não se envolveu com partidos políticos, somente acompanharam o governador durante o mandato, mostrando uma fidelidade ao governador, o que faz sentido visto que são cargos de nomeação do governador, e apresenta um alto grau de localismo.

A trajetória dos deputados estaduais é diferente, visto que $78 \%$ tinham alguma experiência política prévia, com o tempo de carreira bem distribuído entre eles. A maioria nasceu no interior ou outro estado e foi migrando para Curitiba no decorrer de suas carreiras. 63\% tiveram seu primeiro cargo no nível municipal, maioria com cargos legislativos e eletivos, e com carreira parlamentar pura. A taxa de reapresentação é de $82 \%$, o que indica uma tendência de institucionalização do 
parlamento estadual. Recebem mais apoios de políticos do que de outras instituições durante o mandato.

A elite partidária do período tem a carreira mais extensa em relação às outras elites dessa obra, com $64 \%$ com mais de cinco anos de carreira. $75 \%$ tiveram seu primeiro cargo sendo eletivo e a maioria em Curitiba. Já seu último cargo antes de assumirem seu posto foi fora do estado, cargos a nível federal. $42 \%$ tinham sido presidentes de partido, configurando uma elite experiente. Metade em partidos de centro e metade tiveram cargos em instituições sociais/culturais. São os "caciques" de seus partidos no Paraná.

Na Parte III: Os valores políticos das elites paranaenses, os autores acreditam que as atitudes e orientações de uma elite são decisivas na conformação do sistema político e enfatizam a relação existente entre os valores e as ações políticas dos indivíduos. Para 92\% dos indivíduos pesquisados, a democracia é sempre a melhor forma de governo. Porém, quando deparados com situações dadas, não é bem assim: para a elite político-administrativa, 33\% aceitam o fim da democracia se houver ameaça generalizada à propriedade privada, $22 \%$ se houver ameaça aos valores morais e religiosos e $25 \%$ se houver ameaça ao Estado pelo crime organizado. Em relação à concepção de democracia, todas as elites estudadas associam muito a democracia ao voto para representantes. Quando questionados sobre procedimentos mais inclusivos, como participação direta, conselhos gestores, orçamento participativo e plebiscitos, a adesão é bem menor. Os conselhos gestores de políticas públicas são os mais aceitos, por estarem mais institucionalizados. Essa elite tem a concepção menos participativa, pela ênfase na concepção técnica. E é a menos igualitária, já que $64 \%$ são contrários às cotas para negros nas Universidades e à reforma agrária. Seu auto-posicionamento não se associa com o partido a que pertencem. Seus valores se explicam pela proximidade ao governador e sua visão tecnicista da política.

Na elite parlamentar, $41 \%$ aceitam o fim da democracia para ameaça à propriedade privada, o mesmo número se aplicando para o descontrole da corrupção e para a ameaça aos valores morais e religiosos. A maioria se coloca favorável às políticas públicas para a promoção de igualdade. $48 \%$ acreditam que a política é muito complexa e deve ser feita apenas pelas lideranças. A ação do Estado deve ser limitada a "serviços básicos". Não é um grupo homogêneo. A maioria se declara de centro-esquerda, posição mais segura no espectro ideológico, pois se preocupa com as questões sociais, mas sem ser radicais. Quem é de direita tende a aceitar mais o fim do regime democrático do que quem é de esquerda. Segundo os autores, os valores políticos das elites regionais interferem na estabilidade do regime. 
Entre a elite partidária, 64\% se posicionam entre extrema-esquerda e centro-esquerda. Costumam se identificar mais à esquerda do que são. As lideranças preferem posições mais neutras e moderadas, com um prestígio da "centro-esquerda". Somente uma pessoa aceita fim da democracia, é a maior adesão à democracia dentre as elites, explicada pela longa carreira política e pela internalização das regras do jogo democrático. Metade concorda com as ampliações na participação e a maioria é a favor de cotas e de reforma agrária. $78 \%$ preferem liberdade à igualdade e o mesmo número acham que o Estado deve dirigir os serviços básicos, deixando o resto às empresas. Ao serem indagados se depois da queda do Muro de Berlim o capitalismo deve ser aceito por todos, $42 \%$ discordam e $42 \%$ concordam. Isso se deve ao fato de que mesmo entre os partidos proletários há uma separação entre dirigentes e dirigidos, o que leva a uma diferenciação de interesses.

A Parte IV: Estudos de caso - o comportamento da elite parlamentar durante a $14^{a}$ Legislatura engloba capítulos com estudos de caso qualitativos que permitem uma análise mais ampla e explicativa sobre as elites e as relações políticas que a envolvem. Os autores consideram a análise das proposições legislativas como um importante indicador das características de comportamento parlamentar e do processo decisório governamental, além das relações entre Executivo e Legislativo. Com essa análise pretendem responder se há um equilíbrio entre os poderes ou uma dominância do Executivo. Visto que o Legislativo tem uma enorme quantidade de proposições legislativas, com a grande maioria sendo de "baixa relevância" (leis de "Homenagens e utilidade pública"), ao mesmo tempo em que propõe metade das leis que são consideradas complexas ou relevantes. Isso ocorre porque, apesar do Executivo ter 95\% de proposições relevantes, o número de leis propostas é muito menor que do Legislativo. Não se pode dizer, portanto, que o Legislativo é subalterno ao Executivo, nem que exista um "ultrapresidencialismo estadual". O que existe são negociações, em um sistema político que favorece o clientelismo, e o governador, mesmo com um bom funcionamento de sua base parlamentar, precisa do apoio de sua base em troca de recursos para a base eleitoral dos deputados da base.

O capítulo seguinte analisa a cobertura do jornal Gazeta do Povo ao longo da $14^{\mathrm{a}}$ Legislatura para analisar o comportamento parlamentar. No total do período, foram registradas 9848 entradas, dando pouco mais de um quarto de página por dia. A cobertura durante o período eleitoral é bem maior e mais significativa. Em relação ao formato de matéria, há um predomínio de colunas assinadas. A visibilidade não é homogênea entre os sessenta e dois deputados contando a influência pessoal e o peso institucional nessa variável. As áreas de produção legislativa com iniciativa do 
Executivo têm alto valor de noticiabilidade. $83 \%$ das entradas não cobrem o processo decisório, sendo a cobertura mais episódica. Os autores concluem que o jornal não demonstrou muito interesse por política.

O último capítulo é um estudo de caso da venda da Copel, o principal assunto durante a $14^{\mathrm{a}}$ legislatura, analisando as ações dos adversários no campo do conflito político. Antes desse episódio, a Alep se configurava com quarenta deputados na bancada de apoio ao governo e quatorze na oposição. A lei de privatização foi aprovada facilmente, o auge do embate foi a apresentação para apreciação da Assembléia de um projeto de lei de iniciativa popular para revogar a lei de privatização. A estratégia da oposição foi ampliar o debate para a sociedade civil, enquanto o governo tentava restringir a decisão aos técnicos. A oposição se aproveitou de uma crise na base governista devido a repasse de verbas, e ampliou o debate, criando o "Fórum popular contra a venda da Copel" propondo plebiscitos e realizando diversas ações, como uma grande marcha com milhares de pessoas. Depois de um grande embate político a Alep ficou com 29 deputados pró governo e 24 na oposição.

A obra Quem Governa? tem muito a contribuir para os estudos das elites políticas e dos grupos dominantes na sociedade, tanto por seus capítulos com estudos quantitativos, contribuindo com uma boa base de dados para os estudos sociológicos paranaenses, quanto por seus capítulos com estudos qualitativos, mostrando a dinâmica e os mecanismos internos do jogo político, trazendo elementos para análise não só do período estudado, mas para estudos sobre teoria democrática e muito mais. A principal ressalva são as afirmações acerca da hereditariedade na elite, que, principalmente por não ser objetivo do trabalho, não podem ser feitas sem estudos mais detalhados, como os feitos pelo Núcleo de Estudos Paranaenses da Universidade Federal do Paraná, que longe de serem opostos, trazem muitas contribuições que podem se complementar para o desenvolvimento do campo. 